\title{
The Strategy of New Product Introduction in Durable Goods with Secondary Market: Application of the Optimization Method to Supply Chain Problem
}

\author{
Pei Zhao ${ }^{1,2}$ and Zhongkai Xiong ${ }^{1,2}$ \\ ${ }^{1}$ School of Economics and Business Administration, Chongqing University, Chongqing 400044, China \\ ${ }^{2}$ Chongqing Key Laboratory of Logistics, Chongqing University, Chongqing 400044, China \\ Correspondence should be addressed to Zhongkai Xiong; chinawbo@gmail.com
}

Received 13 November 2013; Accepted 13 January 2014; Published 13 March 2014

Academic Editor: Miroslaw Lachowicz

Copyright ( 92014 P. Zhao and Z. Xiong. This is an open access article distributed under the Creative Commons Attribution License, which permits unrestricted use, distribution, and reproduction in any medium, provided the original work is properly cited.

\begin{abstract}
The aim of this paper is to address how the secondary market affects the strategy of the manufacturer's new product introduction by using the optimization method. To do so, we develop a two-period model in which a monopolistic manufacturer sells its new durable products directly to end consumers in both periods, while an entrant operates a reverse channel selling used products in the secondary market. We assume that the manufacturer launches a higher quality product in the second period for the technological innovation. We find that the secondary market can actually increase the manufacturer's profitability and drives the new product introduction in the second period. We also derive the effect of the durability and the degree of quality improvement on the pricing of supply chain partners.
\end{abstract}

\section{Introduction}

Secondary markets have grown significantly as important transaction channels for durable products, such as used car markets, computer markets, and data storage equipment markets. At the same time, secondary markets that are not directly controlled by the manufacturers of new products have also increased greatly. For instance, in 2005, Computer Business Review [1] has reported that third-party companies have built $\$ 100+$ million per year businesses in buying used computer equipment, selling it, or leasing it out to someone else.

The rise of secondary markets implies that the primary markets' manufacturers are facing fierce competition from their secondary markets. Because the existence of resale value for used products facilitates some new products' consumers turning to buy used products, it results in the decreasing of the new-product manufacturer's profitability. Therefore, many manufacturers try to eliminate their secondary markets to alleviate this conflict. For instance, Sun Microsystems, one of the leading firms in the IT server business, deliberately attempted to eliminate the secondary market for its machines worldwide through their pricing and licensing schemes [2]. Another example is Apple Company, that offers consumers free engraving for their new products to weaken the secondary market; for example, new apple products can be graved with the customer's name or pictures according to his/her personalized preferences [3]. However, the opposite opinion is the secondary market which actually benefits the manufacturer's profitability, because it provides resale value for the first-generation buyers to unload their old products. Therefore, it is not immediately apparent how a durable good manufacturer should take into account the cannibalizing effect of the secondary market when choosing its optimal pricing and new product introduction strategies.

In this paper, we develop a two-period model in which a monopolistic manufacturer sells its new durable products directly to end consumers in both periods, while an entrant operates a reverse channel selling used products in the secondary market. We assume that, in the second period, the manufacture releases a quality improvement product (i.e., one that is technologically superior to the version introduced 
in the first period). Our primary objective is to understand the following problems. How does the secondary market affect the manufacturer's profitability and new product introduction in durable goods industry? What is the effect of the durability and the degree of quality improvement on the pricing of supply chain partners?

The rest of this paper is organized as follows. In Section 2, we review the related literature. In Section 3, we describe the model framework and the key elements in our model, and we also derive consumer demand. In Section 4, we provide the optimal equilibrium solutions for channel partners; we also report our main findings in the paper. In Section 5, we conclude the paper and suggest future research opportunities.

\section{Literature Review}

Our paper belongs to the larger literature on durable goods pricing and new product introduction. There are two streams of literature relevant to our research.

The first stream of literature deals with durable products in the secondary market domains. Earlier research about secondary markets in the field of economics focuses on the theory of auctions $[4,5]$. However, our current paper researching the secondary markets is in the operations management area, with our mainly focus being on the impact of the secondary markets on the strategies of manufacturers in the durable goods industry. Anderson and Ginsburgh [6] study that the monopolist uses the secondary market as an indirect device to achieve a form of second-degree price discrimination. They construct a model with heterogeneous consumer valuations. This heterogeneity allows the monopolist to achieve price discrimination through unused and used products. Subsequently, Dhebar [7] analyzes the case wherein a monopolist supplies a series of durable products of increasing quality to a heterogeneous customer base and shows that intertemporal price discrimination issues in such circumstances could prevent a producer from credibly committing to future prices and qualities. More related literature refers to [8-11]. However, all of these studies focus on comparing leasing and selling of durable goods, under a variety of settings (e.g., horizontal competition or the presence of complementary goods). Moreover, they assume that the used market generates no profits for channel members or that used products are sold outside the standard channel. In contrast to these studies, in our model, we assume that consumers have heterogeneous valuations for quality so that used product markets play an allocated role, and there is an active secondary market.

Another stream of literature related to this paper deals with new product strategies for durable products. Levinthal and Purohit [12] analyze different ways a monopolist can market a durable good. They find that, if the quality improvement is small, the monopolist would get more profits by stopping the production of the early version, but in the case of a major improvement, the firm would prefer a buy-back policy. Fudenberg and Tirole [13] consider a richer market structure, but with Levinthal and Purohit [12], they assume that exogenous technological progress drove the introduction

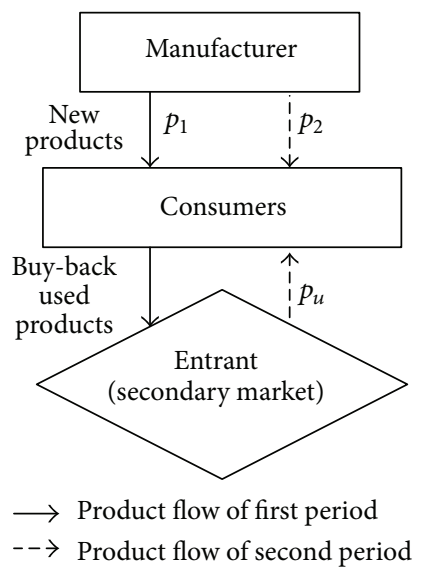

FIGURE 1: Two-period model framework.

of upgrades. Lim and Tang [14] developed a model to analyze the profits associated with a two-product rollover strategy: a single-product rollover and a dual-product rollover. They found the optimal prices of products as well as the time to launch the new product and the time to phase out the old product. Much more literature can be seen in [15-17]. In contrast to these studies, our model considers the new product introduction strategy of the manufacturer in durable goods with the secondary market.

\section{Model Framework}

We focus on a dynamic, two-period model in which a monopolistic manufacturer directly sells its new durable products to the end consumers, while an entrant in the secondary market sells used products (i.e., which were bought back from the first-period customers, cleaned and tested, and resold) to the end consumers (see Figure 1). In the first period, the manufacturer sells the first-generation new durable goods to consumers, who have the option of keeping their used products in the second period or selling them to the entrant for the resale value at the end of first period. In the second period, the manufacturer markets the second-generation new products for technological innovation. Therefore, in the first period, only new durable goods are available. In the second period, new or used goods are available simultaneously. We assume that the manufacturer does not engage in selling used products, and we also assume that the entrant generates a reverse cost $c$ from bought back used products for profitable resale. We normalize the manufacturer and the entrant's marginal cost of production and selling to zero without further loss of generality. Hereinafter, for convenience, we use pronouns "he" and "she" to refer to the manufacturer and the entrant, respectively.

Like most papers [18-20], we assume that all players of the model are rational. Moves of the manufacturer and the entrant follow the Stackelberg game: in the first period, the manufacturer decides the unit price of first-generation new products $p_{1}$, and then the entrant buys back used product from the first-period consumers with cost $c$. In the second period, the manufacturer first determines the unit price of 
second-generation new products $p_{2}$, and then the entrant sets the resale price of used products $p_{u}$.

Before processing a detailed analysis of this model, we make the following assumptions that build on assumptions commonly used in the durable goods literature (e.g., $[8,9])$.

Assumption 1. The product depreciates with use.

In our model, a durable product provides two periods of service. After a consumer purchases a new product in period 1 , the product depreciates with use and becomes a used product in period 2. The rate of depreciation of a product depends on its durability, which is parameterized by $\delta(0 \leq$ $\delta \leq 1)$. If $\delta=1$, the product does not deteriorate and new units are identical to used units. If $\delta=0$, then the product has no durability and it deteriorates fully after one period of use.

Assumption 2. Consumers are heterogeneous in willingness to pay.

We assume that consumer types are distributed uniformly in the interval $[0,1]$, where a consumer of type $v \in[0,1]$ has a willingness to pay off $\nu$ for a new product. In any period, each consumer uses at most one unit (see, [21]).

\section{Assumption 3. Consumers are strategic.}

We assume that consumers take into account the future resale value of the product in making their purchase decisions. This is facilitated in practice by the existence of consulting companies that offer resale value forecasts and it is consistent with the durable goods literature. Our equilibrium characterization is based on rational expectations of consumers about future prices.

Assumption 4. Consumers do not sell their used products directly to each other.

This assumption reflects the current practice in the used products market, such as used PCs and used car markets, where most used equipment, before it can be resold, requires testing and the replacement of wearable parts that the consumers do not have the technical capability to perform (see, [22]). Thus, we assume that consumers cannot sell their used products directly to each other.

Assumption 5. In the second period, the manufacturer introduces a new product that is technologically equivalent or superior to the one introduced in the first period.

In our model, we assume that, in the second period, the manufacturer introduces a new product that is technologically equivalent or superior to the one introduced in period 1 . For instance, an upgraded version might have a faster central processing unit or a bigger memory. To capture the increased consumer willingness to pay for the new product due to this technology improvement, we assume that a consumer with a willingness to pay $v$ for the new product in the first period has a willingness to pay $\alpha \nu$, where $\alpha \geq 1$, for a new product in the second period. Note that we denote the degree of quality improvement with $\alpha$.

Consumer Demand. In our model, we normalize the mass of the first-period consumers to unity. In the second period, we assume a new group of consumers whose mass is $R(>0)$ enters the market. The distribution of their types is also uniformly over $[0,1]$. For the sake of generality, we allow $R$ to be equal to 1 . We can then derive the inverse demand functions from the consumer utility functions.

To maximize utility, a first-period consumer will purchase in the first period if the net utility from buying the good is greater than the utility of not buying the good (which is normalized to zero). Thus, the utility of buying a new good in the first period is $u_{1 n}=v-p_{1}+\delta v(\mathrm{Al})$, where the value $\delta v$ is a consumer place on keeping the good after the first period and $p_{1}$ is the retail price of the first-generation product.

In the second period, there are three mutually exclusive and exhaustive consumer segments (see Figure 2): new consumers, first-period buyers, and first-period nonbuyers. Given the lifetime values of different products, new consumers will buy the new product if they can derive higher net utility than from purchasing the old product on the secondhand market. That is, $\alpha v-p_{2}>\delta v-p_{u}$ (A2). Similarly, first-period buyers will buy the second-generation new product and sell their old products in the secondary market if $\alpha v-p_{2}+c>\delta v(\mathrm{~A} 3)$. Note that $c$ is the residual value obtained by the first-period consumers, who sell their used products to the entrant in the secondary market. Finally, some new consumers and first-period nonbuyers will buy the old product from the secondhand market if they can derive positive net utility. That is, $\delta v-p_{u}>0$ (A4).

Based on the purchase decisions (A1), (A2), (A3), and (A4), we can determine the critical indices shown in Figure 2 as follows: $v_{n 1}=\left(p_{2}-c\right) /(\alpha-\delta), v_{n 2}=\left(p_{2}-p_{u}\right) /(\alpha-\delta)$, $v_{s 1}=v_{s 2}=p_{u} / \delta, v_{1}=p_{1} /(1+\delta)$. Hence, we have $q_{2 n}=$ $1-v_{n 1}=1-\left(p_{2}-c\right) /(\alpha-\delta), q_{n 2}=1-v_{n 2}=1-\left(p_{2}-p_{u}\right) /(\alpha-\delta)$, $q_{u}=v_{1}-v_{s 1}+v_{n 2}-v_{s 2}=p_{1} /(1+\delta)+\left(p_{2}-p_{u}\right) /(\alpha-\delta)-2\left(p_{u} / \delta\right)$, $q_{1}=1-v_{1}=1-p_{1} /(1+\delta)$, where $q_{2 n}$ denotes the quantity of the first-generation buyers who sell their used product and buy a second-generation product in the second period, $q_{n 2}$ denotes the quantity of the first-generation nonbuyers who buy a second-generation product in the second period, $q_{u}$ denotes the quantity of consumers who buy a used product in the second period, and $q_{1}$ denotes the quantity of consumers who buy a first-generation product in the first period.

\section{Model Development}

In this section, we analyze the model of a monopolistic manufacturer directly selling his new durable products to the end consumers in both periods and an entrant selling used products in the secondary market in the second period. In the first period, the manufacturer sells the first-generation new products. In the second period, he sells the second-generation new products to consumers for the technological innovation. We provide a characterization of the equilibrium and focus on the analytical results along the following dimensions. (a) How does the secondary market affect the strategy of the 


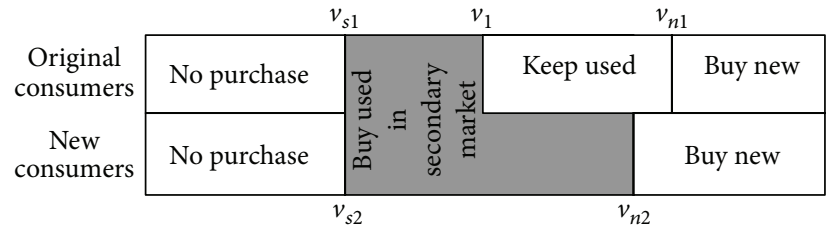

FIGURE 2: Purchase behavior of different segments.

manufacturer's new products introduction? (b) What is the impact of the durability on the pricing of new products?

To ensure that we find a subgame perfect Nash equilibrium, we follow the method of backwards induction. We first solve the entrant's optimization problem and assume rational expectations on the part of the consumers. Letting $\Pi_{e}$ denote the entrant's profit, we can formulate the entrant's problem as follows:

$$
\begin{aligned}
\underset{p_{u}}{\operatorname{Max}} \quad \Pi_{e}\left(p_{1}, p_{2}, p_{u}\right)= & p_{u} q_{u}-c q_{2 n} \\
= & p_{u}\left(v_{1}-v_{s 1}+v_{n 2}-v_{s 2}\right) \\
& -c\left(1-v_{n 1}\right)
\end{aligned}
$$

subject to $0<q_{u} \leq q_{2 n}$,

where the constraint $q_{u} \leq q_{2 n}$ ensures that the sales quantity of used products is not greater than the number of units that can be collected from the consumers and $p_{u}, c$ are the price of used products and the buy-back cost of unit used product for the entrant, respectively. Note that the entrant would not participate in the secondary market in the second period, when $q_{u}=0$ (i.e., there is no secondary market existing in the second period). This case is not the aim of our research.

The manufacturer's problem is to maximize the total profit over the two periods with respect to $p_{1}, p_{2}$, taking into account the entrant's best response function and the consumers' two-period strategies. In order to obtain the subgame perfect Nash equilibrium, we follow the method of backwards induction. We first solve the manufacturer's second-period problem and then solve the first-period problem. Let $\Pi_{1}$ and $\Pi_{2}$ denote the manufacturer's first-period and second-period profits, respectively. The manufacturer's second-period optimization problem is

$$
\begin{aligned}
\operatorname{Max}_{p_{2}} \Pi_{2}\left(p_{1}, p_{2}, p_{u}^{*}\right) & =p_{2}\left(q_{2 n}+q_{n 2}\right) \\
& =p_{2}\left(1-v_{n 1}+1-v_{n 2}\right),
\end{aligned}
$$

where $p_{2}$ denotes the price of the second-generation new product in period 2 and the expressions for all quantities take into account the entrant's best response $p_{u}^{*}$.

The manufacturer's first-period optimization problem is

$$
\begin{aligned}
\underset{p_{1}}{\operatorname{Max}} \Pi\left(p_{1}, p_{2}^{*}, p_{u}^{*}\right) & =\Pi_{1}\left(p_{1}, p_{2}^{*}, p_{u}^{*}\right)+\Pi_{2}^{*}\left(p_{1}, p_{2}^{*}, p_{u}^{*}\right) \\
& =p_{1}\left(1-v_{1}\right)+\Pi_{2}^{*}\left(p_{1}, p_{2}^{*}, p_{u}^{*}\right),
\end{aligned}
$$

where the first form is the revenue of the manufacturer in period 1 and the second form is the optimal profit of the manufacturer in period 2.

The equilibrium decisions for the channel partners are given in Proposition 6. Note that all the technical analysis for the paper is provided in the Appendix.

Proposition 6. Equilibrium decisions for the channel partners in model are

$$
\begin{aligned}
p_{1}^{*}=2 & (1+\delta)(2 \alpha-\delta) \\
\times & \left(18 \alpha \delta+16 \alpha-12 \delta^{2}-10 \delta+c \delta\right) \\
\times & \left(128 \alpha^{2}(1+\delta)-144 \alpha \delta\right. \\
& \left.+40 \delta^{2}-145 \alpha \delta^{2}+41 \delta^{3}\right)^{-1}, \\
p_{2}^{*}=2(1+\delta)\left[32 \alpha^{3}-62 \alpha^{2} \delta+37 \alpha \delta^{2}\right. & \left.-7 \delta^{3}+c\left(16 \alpha^{2}-16 \alpha+4 \delta^{2}\right)\right] \\
\times & \left(128 \alpha^{2}(1+\delta)-144 \alpha \delta\right. \\
& \left.+40 \delta^{2}-145 \alpha \delta^{2}+41 \delta^{3}\right)^{-1}, \\
p_{u}^{*}=\delta[ & 34 \alpha^{2} \delta+32 \alpha^{2}-53 \alpha \delta^{2}-49 \alpha \delta+19 \delta^{3} \\
& \left.+17 \delta^{2}+c\left(9 \alpha \delta+8 \alpha-4 \delta-5 \delta^{2}\right)\right] \\
\times & \left(128 \alpha^{2}(1+\delta)-144 \alpha \delta+40 \delta^{2}\right. \\
& \left.-145 \alpha \delta^{2}+41 \delta^{3}\right)^{-1} .
\end{aligned}
$$

Proposition 6 shows the equilibrium decisions for the channel partners when the secondary market exists. It is worth noting that the strategy of the manufacturer launching an innovative new product in the second period relates to the durability of first-generation used products and buy-back cost of used products for the entrant. Moreover, the price of the first-generation and second-generation new products and first-generation used product all increases in the reverse cost of the entrant.

Proposition 7. The price of the first-generation new and used products increases in the durability of products $\delta$, while the price of the second-generation new products decreases in the durability of products $\delta$.

The higher durability, $\delta$, means the higher quality of the first-generation new products, in turn, which facilitates the manufacturer charges a higher price for the first-generation new products. On the other hand, as the durability of the firstgeneration new product increases, it becomes more expensive for the entrant to obtain the used products and, in turn, the market of the first-generation used products becomes less viable and its size decreases. Hence, this will improve the resale price of used products for the entrant. In addition, because of the imperfect substitutability of new and used 


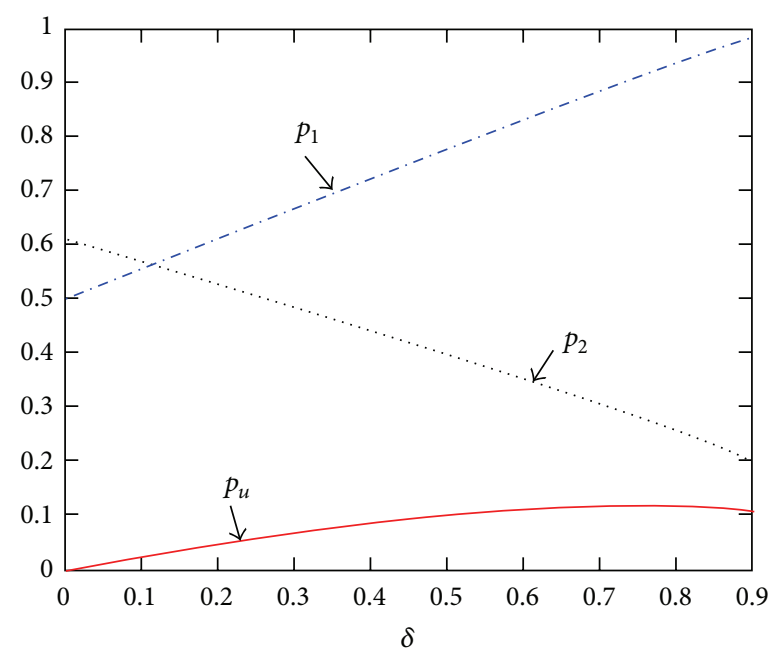

FIgURE 3: Changing trends in price.

products, the supply of the first-generation product on the secondhand market competes with the second-generation product. Moreover, as the durability of the first-generation new product increases, the competitiveness of the firstgeneration used products and the second-generation new products is stronger. Hence, the manufacturer is forced to charge a lower price of the second-generation new product to customers. For the intuition underlying this proposition, we also give Figure 3 (i.e., $\alpha=1.2, c=0.05$ ), which displays the changing trends of the price of the first-generation and second-generation new products and first-generation used products.

Proposition 8. The price of the first-generation and secondgeneration new products and the first-generation used products all increases in the degree of quality improvement $\alpha$.

The intuition behind this result is as follows. When the secondary market exists, more first-generation buyers prefer to buy a second-generation new product in the second period, because they get a residual value to inspire them to buy a second-generation new product by selling their used product to the secondary market. Hence, the existence of the secondary market stimulates more first-generation buyers to replace their used product with a second-generation new product. In other words, the manufacturer has a higher opportunity to charge a higher price. On the other hand, in order to encourage more first-generation buyers to buy a second-generation new product in the second period, the manufacturer prefers an active secondary market for the firstperiod buyers to unload their old products. Therefore, to achieve this result, the manufacturer will increase its price of the first-generation new product, because improving the price of the first-generation new product results in two effects on the secondary market. First, on the demand side, a higher first-generation price will increase the future demand for the first-generation product in the secondary market because more first-period customers will wait till the second period to buy the old product on the secondary market. Second, on the supply side, the supply of the first-generation product on the secondary market will be reduced. The reason is that the first-period price is higher. Hence, fewer units are sold in the first period. These effects reinforce each other and lead to a higher price in the secondary market. In addition, we illustrate the changing trends of the price of the firstgeneration and second-generation new products and the first-generation used products through a broad numerical study. Table 1 (i.e., $\delta=0.6, c=0.05$ ) summarizes the price of different products with the degree of quality improvement $\alpha$ between 1.1 and 1.9.

Proposition 9. When there is a secondary market, the profit of the manufacturer is increasing in the degree of quality improvement. That is, the existence of the secondary market drives the manufacturer to launch a quality improvement new product in the second period.

To understand this result, one needs to recognize how the secondary market affects the manufacturer's profitability. On the one hand, because the secondary market offers a resale value to the first-generation buyers, more of them buy a second-generation new product in the second period. This facilitates for the manufacturer charging a higher price for his second-generation new product. On the other hand, if the secondary market exists, the first-generation product competes with the manufacturer's second-generation new product in the second period. This cannibalization effect puts downward pressure on the manufacturer's profitability. Therefore, the net effect of the secondary market on the manufacturer's profitability depends on which of the two opposing forces is stronger. As the degree of quality improvement of the second-generation new product increases, the positive effect of the secondary market on the first-generation buyers dominates its cannibalization effect on the second-generation new products. Hence, the existence of the secondary market actually increases the manufacturer's profitability and drives the manufacturer to launch an innovative new product in the second period.

\section{Conclusion}

In this paper, we consider a dynamic, two-period model in which a monopolistic manufacturer directly sells new durable products to the end consumers, and an entrant sells used products to them. In the first period, the manufacturer sells the first-generation new products to consumers. In the second period, he sells the second-generation new products to consumers for technological innovation. We assume that the manufacturer does not engage in selling used products in the second period. We examine how the secondary market affects the strategy of the manufacturer's new product introduction in durable goods industry. The significant difference with the previous research is that we consider the endogeneity of the consumer's decision and its impact on the demand of consumers, which, we believe, is a novel addition to the literature. In this context, our study brings to light a number of important implications of secondary markets on the new introduction for the durable products. One of the important 
TABLE 1: Different price value for parameter $\alpha$.

\begin{tabular}{cccccccccc}
\hline$p_{i}$ & & & & & $\alpha$ & & & \\
& 1.1 & 1.2 & 1.3 & 1.4 & 1.5 & 1.6 & 1.7 & 1.8 \\
\hline$p_{1}$ & 0.8284 & 0.8296 & 0.8305 & 0.8312 & 0.8318 & 0.8323 & 0.8327 & 0.8331 \\
$p_{2}$ & 0.3030 & 0.3550 & 0.4066 & 0.4579 & 0.5089 & 0.5598 & 0.6015 & 0.6612 & 0.8334 \\
$p_{u}$ & 0.1054 & 0.1110 & 0.1155 & 0.1191 & 0.1221 & 0.1246 & 0.1268 & 0.1286 & 0.1302 \\
\hline
\end{tabular}

conclusions is the existence of the secondary market deriving the new product introduction in durable goods industry.

Our model setting assumed a renewable set of consumers. An extension of our model would be set as a nonrenewable market, which is a typical assumption in the durable product literature. Another assumption in our model is that the manufacturer does not engage in selling used products in the secondary market. We can consider the manufacturer selling new and used products, simultaneously. We hope that this work will spur a stream of research regarding the important and ever-increasing role that secondary markets play in the durable goods industry, which will serve to provide guidance to marketing managers.

\section{Appendix}

The entrant's optimization problem is (B-1), where all segment sizes have the functional form defined in the paper. Substituting these segment sizes into (B-1), we find that $\partial^{2} \Pi_{e}\left(p_{u}\right) / \partial p_{u}^{2}<0$. Therefore, the profit function is concave in $p_{u}$. The Lagrangian for the entrant's problem is $L_{e}\left(p_{u}, \lambda_{1}\right)=$ $p_{u}\left(p_{1} /(1+\delta)+\left(p_{2}-p_{u}\right) /(\alpha-\delta)-2\left(p_{u} / \delta\right)\right)-c\left(1-\left(p_{2}-\right.\right.$ $c) /(\alpha-\delta))+\lambda_{1}\left(1-\left(p_{2}-c\right) /(\alpha-\delta)-p_{1} /(1+\delta)-\left(p_{2}-\right.\right.$ $\left.\left.p_{u}\right) /(\alpha-\delta)+2\left(p_{u} / \delta\right)\right)$ and the KKT conditions for optimality are $\partial L_{e}\left(p_{u}, \lambda_{1}\right) / \partial p_{u}=p_{u}(-1 /(\alpha-\delta)-2 / \delta)+p_{1} /(1+\delta)+\left(p_{2}-\right.$ $\left.p_{u}\right) /(\alpha-\delta)-2\left(p_{u} / \delta\right)+\lambda_{1}(1 /(\alpha-\delta)+2 / \delta)=0 ; \lambda_{1}\left(q_{2 n}-q_{u}\right)=$ $\lambda_{1}\left(1-\left(p_{2}-c\right) /(\alpha-\delta)-p_{1} /(1+\delta)-\left(p_{2}-p_{u}\right) /(\alpha-\delta)+2\left(p_{u} / \delta\right)\right)=$ $0 ; 0<q_{u} \leq q_{2 n}$.

We consider two subcases according to whether the Lagrangian multiplier $\lambda_{1}$ is greater than or equals zero or not.

Case $E-a\left(\lambda_{1}=0\right)$. Simultaneously solving for the above equations, we have that $p_{u}^{*}=\delta\left[(\alpha-\delta) p_{1}+(1+\delta) p_{2}\right] / 2(1+\delta)(2 \alpha-$ $\delta)$. Meanwhile, the constraint $0<q_{u} \leq q_{2 n}$ leads to $0<p_{2} \leq$ $\left(2(1+\delta)(\alpha-\delta+c)-(\alpha-\delta) p_{1}\right) / 3(1+\delta)$. Thus, when $0<$ $p_{2} \leq\left(2(1+\delta)(\alpha-\delta+c)-(\alpha-\delta) p_{1}\right) / 3(1+\delta)$, the entrant will choose $p_{u}^{*}=\delta\left[(\alpha-\delta) p_{1}+(1+\delta) p_{2}\right] / 2(1+\delta)(2 \alpha-\delta)$.

Case $E-b\left(\lambda_{1}>0\right)$. Simultaneously solving for the above equations, we have that $p_{u}^{*}=\delta\left[(1+\delta)\left(2 p_{2}+\delta+c-\alpha\right)+(\alpha-\delta) p_{1}\right] /(1+$ $\delta)(2 \alpha-\delta), \lambda_{1}=\delta\left[(1+\delta)\left(4 c-3 p_{2}\right)+(\alpha-\delta)\left(4+4 \delta-5 p_{1}\right)\right] / 3(1+$ $\delta)(2 \alpha-\delta)$.

Because the Lagrangian multiplier $\lambda_{1}=\delta[(1+\delta)(4 c-$ $\left.\left.3 p_{2}\right)+(\alpha-\delta)\left(4+4 \delta-5 p_{1}\right)\right] / 3(1+\delta)(2 \alpha-\delta)>0$, we have $0<p_{2} \leq\left(4(1+\delta)(\alpha-\delta+c)-5 p_{1}(\alpha-\delta)\right) / 3(1+\delta)$.

We now consider the price of new products in the second period under Case E-a. Replacing the values $p_{u}^{*}=\delta\left[(\alpha-\delta) p_{1}+\right.$ $\left.(1+\delta) p_{2}\right] / 2(1+\delta)(2 \alpha-\delta)$ and constraint in Case E-a, we obtain the manufacturer's second-period problem as

$$
\begin{aligned}
& \operatorname{Max} \\
& \Pi_{2}\left(p_{2}\right)=p_{2}\left(q_{2 n}+q_{n 2}\right) \\
& =p_{2}\left(1-\frac{p_{2}-c}{\alpha-\delta}+1-\frac{p_{2}-p_{u}^{*}}{\alpha-\delta}\right) \\
& \text { subject to } 0<p_{2} \leq \frac{2(1+\delta)(\alpha-\delta+c)-(\alpha-\delta) p_{1}}{3(1+\delta)} \text {, }
\end{aligned}
$$

where all segment sizes have the functional form defined in the paper. Substituting these segment sizes into the manufacturer's second-period problem (A.la), we find that $\partial^{2} \Pi_{2}\left(p_{2}\right) / \partial p_{2}^{2}<0$. Therefore, the profit function is concave in $p_{2}$.

The Lagrangian for the manufacture's second-period problem is

$$
\begin{aligned}
& L_{2}\left(p_{2}, \lambda_{2}\right) \\
& =p_{2}\left(1-\frac{p_{2}-c}{\alpha-\delta}+1-\frac{p_{2}-p_{u}^{*}}{\alpha-\delta}\right) \\
& \quad-\lambda_{2}\left(\frac{2(1+\delta)(\alpha-\delta+c)-(\alpha-\delta) p_{1}}{3(1+\delta)}-p_{2}\right),
\end{aligned}
$$

and the Kuhn-Tucker conditions for optimality are

$$
\begin{gathered}
\frac{\partial L_{2}\left(p_{2}, \lambda_{2}\right)}{\partial p_{2}}=1-\frac{p_{2}-c}{\alpha-\delta}+1-\frac{p_{2}-p_{u}^{*}}{\alpha-\delta}-\frac{2 p_{2}}{\alpha-\delta} \\
+\frac{\delta p_{2}}{2(\alpha-\delta)(2 \alpha-\delta)}+\lambda_{2}=0 \\
\lambda_{2}\left(\frac{2(1+\delta)(\alpha-\delta+c)-(\alpha-\delta) p_{1}}{3(1+\delta)}-p_{2}\right)=0 \\
0<p_{2} \leq \frac{2(1+\delta)(\alpha-\delta+c)-(\alpha-\delta) p_{1}}{3(1+\delta)}
\end{gathered}
$$

We consider two subcases according to whether the Lagrangian multiplier $\lambda_{2}$ is greater than or equals zero or not.

Case $M_{2}-a-1\left(\lambda_{2}=0\right)$. Simultaneously solving for the above equations, we have that

$$
p_{2}^{*}=\frac{2(1+\alpha)\left(4 \alpha^{2}-6 \alpha \delta+2 \delta^{2}+2 c \alpha-c \delta\right)+\delta p_{1}(\alpha-\delta)}{2(1+\delta)(8 \alpha-5 \delta)} .
$$


In addition, the constraint $0<p_{2} \leq(2(1+\delta)(\alpha-\delta+c)-(\alpha-$ $\left.\delta) p_{1}\right) / 3(1+\delta)$ leads to

$$
0<p_{1} \leq \frac{(1+\delta)}{2(\alpha-\delta+c)(\alpha-\delta)}
$$

Case $M_{2}-a-2\left(\lambda_{2}>0\right)$. The Kuhn-Tucker conditions for optimality are

$$
\begin{gathered}
\frac{\partial L_{2}\left(p_{2}, \lambda_{2}\right)}{\partial p_{2}} \\
=1-\frac{p_{2}-c}{\alpha-\delta}+1-\frac{p_{2}-p_{u}^{*}}{\alpha-\delta}-\frac{2 p_{2}}{\alpha-\delta} \\
\quad+\frac{\delta p_{2}}{2(\alpha-\delta)(2 \alpha-\delta)}+\lambda_{2}=0, \\
p_{2}^{*}=\frac{2(1+\delta)(\alpha-\delta+c)-(\alpha-\delta) p_{1}}{3(1+\delta)} .
\end{gathered}
$$

Solving the system, we have that

$$
\begin{aligned}
\lambda_{2}=\left(19 \alpha \delta p_{1}+12 c \alpha \delta-2 \alpha \delta+2 \delta^{2}-8 c \delta-2 \alpha \delta^{2}\right. \\
\left.-12 \alpha^{2} p_{1}+12 c \alpha-7 \delta^{2} p_{1}-8 c \delta^{2}+2 \delta^{3}\right) \\
\times(6(1+\delta)(\alpha-\delta)(2 \alpha-\delta))^{-1} .
\end{aligned}
$$

Moreover, Lagrangian multiplier $\lambda_{2}>0$ leads to

$$
\begin{aligned}
& \left(19 \alpha \delta p_{1}+12 c \alpha \delta-2 \alpha \delta+2 \delta^{2}-8 c \delta-2 \alpha \delta^{2}\right. \\
& \left.-12 \alpha^{2} p_{1}+12 c \alpha-7 \delta^{2} p_{1}-8 c \delta^{2}+2 \delta^{3}\right) \\
& \times(6(1+\delta)(\alpha-\delta)(2 \alpha-\delta))^{-1}>0 .
\end{aligned}
$$

That is,

$$
p_{1}>\frac{(1+\delta)\left(6 c \alpha+\delta^{2}-\alpha \delta-4 c \delta\right)}{2(\alpha-\delta)(12 \alpha-7 \delta)} .
$$

Similarly, we consider the price of new products in the second period under Case E-b. Replacing the values $p_{u}^{*}=$ $\delta\left[(1+\delta)\left(2 p_{2}+\delta+c-\alpha\right)+(\alpha-\delta) p_{1}\right] /(1+\delta)(2 \alpha-\delta)$ and constraint in Case E-b, we obtain that the manufacturer's second-period problem is

$$
\begin{aligned}
& \operatorname{Max}_{p_{2}} \quad \Pi_{2}\left(p_{2}\right)=p_{2}\left(q_{2 n}+q_{n 2}\right) \\
& =p_{2}\left(1-v_{n 1}+1-v_{n 2}\right) \text {, } \\
& \text { subject to } 0<p_{2} \leq \frac{4(1+\delta)(\alpha-\delta+c)-5 p_{1}(\alpha-\delta)}{3(1+\delta)} \text {, }
\end{aligned}
$$

where all segment sizes have the functional form defined in the paper. Note that we denote this case in Case $\mathrm{M}_{2}$ b. Substituting these segment sizes into the manufacturer's second-period problem (A.1b), we find that $\partial^{2} \Pi_{2}\left(p_{2}\right) / \partial p_{2}^{2}<$ 0 . Therefore, the profit function is concave in $p_{2}$. Solving the first order derivative of (A.1b), we have that $p_{2}^{*}=\left((1+\delta)\left(8 \alpha^{2}-\right.\right.$ $\left.\left.12 \alpha \delta+4 \delta^{2}-2 c \delta+4 c \alpha\right)+\delta p_{1}(\alpha-\delta)\right) / 2(1+\delta)(8 \alpha-5 \delta)$. Meanwhile, the constraint of (A.1b) is $0<p_{1} \leq 2(1+\delta)\left(14 \delta^{2}-\right.$ $\left.34 \alpha \delta-17 c \delta++20 \alpha^{2}+26 c \alpha\right) /(\alpha-\delta)(80 \alpha-47 \delta)$

Now we consider the price of new products in the first period under Case $\mathrm{M}_{2}$-a-1. Replacing the values $p_{2}^{*}=2(1+$ $\alpha)\left(4 \alpha^{2}-6 \alpha \delta+2 \delta^{2}+2 c \alpha-c \delta\right)+\delta p_{1}(\alpha-\delta) / 2(1+\delta)(8 \alpha-5 \delta)$ and constraint in Case $\mathrm{M}_{2}-\mathrm{a}-1$, we obtain that the manufacturer's first-period problem is

$$
\operatorname{Max} \quad \begin{aligned}
\Pi\left(p_{1}\right) & =\Pi_{1}\left(p_{1}\right)+\Pi_{2}^{*}\left(p_{1}\right) \\
& =p_{1}\left(1-v_{1}\right)+\Pi_{2}^{*}\left(p_{1}\right),
\end{aligned}
$$

subject to $0<p_{1} \leq \frac{(1+\delta)}{2(\alpha-\delta+c)(\alpha-\delta)}$.

where all segment sizes have the functional form defined in the paper. Substituting these segment sizes into the manufacturer's first-period problem (A.2a), we find that $\partial^{2} \Pi_{1}\left(p_{1}\right) / \partial p_{1}^{2}<0$. Therefore, the profit function is concave in $p_{1}$. lem is

The Lagrangian for the manufacture's first-period prob-

$$
\begin{aligned}
L_{1}\left(p_{1}, \lambda_{3}\right)= & p_{1}\left(1-\frac{p_{1}}{1+\delta}\right)+p_{2}^{*}\left(1-v_{n 1}+1-v_{n 2}\right) \\
& -\lambda_{3}\left(p_{1}-\frac{(1+\delta)}{2(\alpha-\delta+c)(\alpha-\delta)}\right) .
\end{aligned}
$$

The Kuhn-Tucker conditions for optimality are

$$
\begin{gathered}
\frac{\partial L_{1}\left(p_{1}, \lambda_{3}\right)}{\partial p_{1}}=1-\frac{2 p_{1}}{1+\delta}+1-\frac{p_{2}^{*}-c}{\alpha-\delta} \\
+1-\frac{p_{2}^{*}-p_{u}^{*}}{\alpha-\delta}-\frac{2 p_{2}^{*}}{\alpha-\delta}-\lambda_{3}=0 ; \\
\lambda_{3}\left(p_{1}-\frac{(1+\delta)}{2(\alpha-\delta+c)(\alpha-\delta)}\right)=0 ; \\
0<p_{1} \leq \frac{(1+\delta)}{2(\alpha-\delta+c)(\alpha-\delta)} .
\end{gathered}
$$

We consider two subcases according to whether the Lagrangian multiplier $\lambda_{3}$ is greater than or equals zero or not.

Case $M_{1}-a-1-1\left(\lambda_{3}=0\right)$. Simultaneously solving for the above equations, we have that

$$
p_{1}^{*}=\frac{2(1+\delta)(2 \alpha-\delta)\left(18 \alpha \delta+16 \alpha-12 \delta^{2}-10 \delta+c \delta\right)}{128 \alpha^{2}(1+\delta)-144 \alpha \delta+40 \delta^{2}-145 \alpha \delta^{2}+41 \delta^{3}}
$$


Case $M_{1}-a-1-2\left(\lambda_{3}>0\right)$. The Kuhn-Tucker conditions for optimality are

$$
\begin{aligned}
& \frac{\partial L_{1}\left(p_{1}, \lambda_{3}\right)}{\partial p_{1}}= 1-\frac{2 p_{1}}{1+\delta}+1-\frac{p_{2}^{*}-c}{\alpha-\delta} \\
&+1-\frac{p_{2}^{*}-p_{u}^{*}}{\alpha-\delta}-\frac{2 p_{2}^{*}}{\alpha-\delta}-\lambda_{3}=0, \\
& p_{1}^{*}= \frac{(1+\delta)}{2(\alpha-\delta+c)(\alpha-\delta)}, \\
& \lambda_{3}\left(p_{1}-\frac{(1+\delta)}{2(\alpha-\delta+c)(\alpha-\delta)}\right)=0 .
\end{aligned}
$$

Solving the system, we have that $\lambda^{3}=1-2(1+\alpha+c-\delta)(4+$ $(\delta-\alpha)(1-2 \delta /(1+\alpha))) /(3+3 \alpha-3 \delta) /(\delta-\alpha)+((2+2 \alpha)((\delta-\alpha)(1+$ $\alpha-\delta)+c(\delta-\alpha)+(1+\alpha+c-\delta)(4+(\delta-\alpha)(1-2 \delta /(1+\alpha)))) /(3+$ $3 \alpha-3 \delta)(1+\alpha-\delta))+(1+\alpha)(1+\alpha-\delta)(1+\alpha+c-\delta)(4+(\delta-\alpha)(1-$ $2 \delta /(1+\alpha))) /(3+3 \alpha-3 \delta)) /(\delta-\alpha) /(2+2 \alpha+(\delta-\alpha)(2+2 \alpha-\delta))$. Using MATLAB 7.0, for a parameter combination, that is, $\alpha=$ $1.2, \delta=0.7, c=0.005$, we get $\lambda_{3}=-2.3628<0$. Therefore, this case will never occur in equilibrium.

Similarly, we consider the price of new products in the first period under Case $\mathrm{M}_{2}-\mathrm{a}-2$. Replacing the values $p_{2}^{*}=$ $\left((1+\delta)\left(8 \alpha^{2}-12 \alpha \delta+4 \delta^{2}-2 c \delta+4 c \alpha\right)+\delta p_{1}(\alpha-\delta)\right) / 2(1+$ $\delta)(8 \alpha-5 \delta)$ and constraint in Case $\mathrm{M}_{2}$-a-2, we obtain that the manufacturer's first-period problem is

$$
\begin{aligned}
& \operatorname{Max} \Pi\left(p_{1}\right)=\Pi_{1}\left(p_{1}\right)+\Pi_{2}^{*}\left(p_{1}\right) \\
&=p_{1}\left(q_{2 n}+q_{n 2}\right)+\Pi_{2}^{*}\left(p_{1}\right) \\
& \text { subject to } \quad p_{1}>\frac{(1+\delta)\left(6 c \alpha+\delta^{2}-\alpha \delta-4 c \delta\right)}{2(\alpha-\delta)(12 \alpha-7 \delta)},
\end{aligned}
$$

where all segment sizes have the functional form defined in the paper. Substituting these segment sizes into the manufacturer's first-period problem (A.2b), we find that $\partial^{2} \Pi_{1}\left(p_{1}\right) / \partial p_{1}^{2}<0$. Therefore, the profit function is concave in $p_{1}$. Solving the first order derivative of (A.2b), we have that $p_{1}^{*}=(4(1+c)+\alpha-\delta) / 6$. It can be shown that $p_{1}^{*}$ does not such that the constraint of (A.2b). Therefore, this case will never occur in equilibrium.

Similarly, we consider the price of new products in the first period Case $\mathrm{M}_{2}-\mathrm{b}$. Replacing the values $p_{2}^{*}=(1+\alpha)[(\delta-$ $\left.\alpha)(1+\alpha-\delta)+(\delta-\alpha) c+p_{1}(1+\alpha-\delta)\right] / 2(1+\alpha-\delta)(1+2 \delta-\alpha)$ and constraint in Case $M_{2}-b$, we obtain that the manufacturer's first-period problem is

$$
\begin{aligned}
\operatorname{Max} & \\
& =p_{1}\left(p_{1 n}\right)=\Pi_{1}\left(p_{1}\right)+\Pi_{2}^{*}\left(p_{1}\right)+\Pi_{2}^{*}\left(p_{1}\right) \\
\text { subject to } \quad 0< & p_{1} \\
\leq & 2(1+\delta) \\
& \times\left(14 \delta^{2}-34 \alpha \delta-17 c \delta+20 \alpha^{2}+26 c \alpha\right) \\
& \times((\alpha-\delta)(80 \alpha-47 \delta))^{-1},
\end{aligned}
$$

where all segment sizes have the functional form defined in the paper. Substituting these segment sizes into the manufacturer's first-period problem (A.2c), we find that $\partial^{2} \Pi_{1}\left(p_{1}\right) /$ $\partial p_{1}^{2}<0$. Therefore, the profit function is concave in $p_{1}$. Solving the first order derivative of (A.2c), we have that $p_{1}^{*}=$ $2(\delta-\alpha)(2+\delta+c) /(1+8 \delta-7 \alpha)$. It can be shown that $p_{1}^{*}$ does not such that the constraint of (A.2c). Therefore, this case will never occur in equilibrium.

Based on the above analysis, we obtain that the optimal price of new products in period 1 is $p_{1}^{*}=2(1+\delta)(2 \alpha-\delta)$ $\left(18 \alpha \delta+16 \alpha-12 \delta^{2}-10 \delta+c \delta\right) /\left(128 \alpha^{2}(1+\delta)-144 \alpha \delta+\right.$ $\left.40 \delta^{2}-145 \alpha \delta^{2}+41 \delta^{3}\right)$.

Substitution of $p_{1}^{*}$ into $p_{2}^{*}$ and $p_{u}^{*}$, we derive

$$
\begin{aligned}
& p_{2}^{*}=2(1+\delta)[ 32 \alpha^{3}-62 \alpha^{2} \delta+37 \alpha \delta^{2} \\
&\left.-7 \delta^{3}+c\left(16 \alpha^{2}-16 \alpha+4 \delta^{2}\right)\right] \\
& \times\left(128 \alpha^{2}(1+\delta)-144 \alpha \delta\right. \\
&\left.+40 \delta^{2}-145 \alpha \delta^{2}+41 \delta^{3}\right)^{-1}, \\
& p_{u}^{*}=\delta\left[34 \alpha^{2} \delta+32 \alpha^{2}-53 \alpha \delta^{2}-49 \alpha \delta+19 \delta^{3}\right. \\
&\left.+17 \delta^{2}+c\left(9 \alpha \delta+8 \alpha-4 \delta-5 \delta^{2}\right)\right] \\
& \times\left(128 \alpha^{2}(1+\delta)-144 \alpha \delta\right. \\
&\left.+40 \delta^{2}-145 \alpha \delta^{2}+41 \delta^{3}\right)^{-1} .
\end{aligned}
$$

Therefore, the equilibrium decisions for the channel partners are given in Remark A.1.

Remark A.1. Entrant's decision is as follows:

$$
\begin{gathered}
p_{u}^{*}=\delta\left[34 \alpha^{2} \delta+32 \alpha^{2}-53 \alpha \delta^{2}-49 \alpha \delta+19 \delta^{3}\right. \\
\left.+17 \delta^{2}+c\left(9 \alpha \delta+8 \alpha-4 \delta-5 \delta^{2}\right)\right] \\
\times\left(128 \alpha^{2}(1+\delta)-144 \alpha \delta\right. \\
\left.+40 \delta^{2}-145 \alpha \delta^{2}+41 \delta^{3}\right)^{-1} .
\end{gathered}
$$

Manufacturer's decisions are as follows.

Period 1:

$$
p_{1}^{*}=\frac{2(1+\delta)(2 \alpha-\delta)\left(18 \alpha \delta+16 \alpha-12 \delta^{2}-10 \delta+c \delta\right)}{128 \alpha^{2}(1+\delta)-144 \alpha \delta+40 \delta^{2}-145 \alpha \delta^{2}+41 \delta^{3}}
$$

Period 2:

$$
\begin{aligned}
p_{2}^{*}=2(1+\delta)[ & 32 \alpha^{3}-62 \alpha^{2} \delta+37 \alpha \delta^{2} \\
& \left.-7 \delta^{3}+c\left(16 \alpha^{2}-16 \alpha+4 \delta^{2}\right)\right] \\
\times & \left(128 \alpha^{2}(1+\delta)-144 \alpha \delta+40 \delta^{2}-145 \alpha \delta^{2}+41 \delta^{3}\right)^{-1} .
\end{aligned}
$$




\section{Proof of Proposition 6. Refer to Remark A.1.}

Proof of Proposition 7. For the sign of $\partial p_{1} / \partial \delta$, we have

$$
\begin{gathered}
\frac{\partial p_{1}}{\partial \delta}=\left(\delta^{4}\left(470+960 \delta+492 \delta^{2}\right)\right. \\
+\alpha \delta\left(9084 \alpha \delta+9216 \alpha^{3}-21436 \alpha^{2} \delta^{2}\right. \\
\left.\left.+18296 \alpha \delta^{2}-3384 \delta^{2}\right)+c f\right) \\
\times\left[128 \alpha^{2}(1+\delta)-144 \alpha \delta\right. \\
\left.+40 \delta^{2}-145 \alpha \delta^{2}+41 \delta^{3}\right]^{-2}
\end{gathered}
$$

where $f=256\left(\alpha^{3} \delta^{2}+\alpha^{3}-\alpha^{2} \delta-\alpha^{2} \delta^{3}\right)+512 \alpha^{3} \delta+64 \alpha \delta^{2}+$ $124 \alpha \delta^{3}-510 \alpha^{2} \delta^{2}+63 \alpha \delta^{4}$.

Noting that $\alpha>\delta$, using MATLAB 7.0, we have that $\partial p_{1} / \partial \delta$ is positive. Hence, the price of first-generation new product increases in the durability $\delta$.

For the sign of $\partial p_{u} / \partial \delta$, we have

$$
\begin{aligned}
\frac{\partial p_{u}}{\partial \delta}=( & \delta^{4}\left(680+1520 \delta+779 \delta^{2}-10784 \alpha\right. \\
& \left.+13587 \alpha^{2}-5510 \alpha \delta\right) \\
& \left.-4896 \alpha \delta^{3}+c f\right) \\
\times & {\left[128 \alpha^{2}(1+\delta)-144 \alpha \delta\right.} \\
& \left.+40 \delta^{2}-145 \alpha \delta^{2}+41 \delta^{3}\right]^{-2} \\
+ & \alpha^{2}\left(4096 \alpha^{2}+12304 \delta^{2}+8704 \alpha^{2} \delta\right. \\
& \left.+27602 \delta^{3}-26880 \alpha \delta^{2}-12544 \alpha \delta\right) \\
\times & {\left[128 \alpha^{2}(1+\delta)-144 \alpha \delta\right.} \\
+ & \left.40 \delta^{2}-145 \alpha \delta^{2}+41 \delta^{3}\right]^{-2}
\end{aligned}
$$

where $f=1024 \alpha^{3}-1024 \alpha^{2} \delta+256 \alpha \delta^{2}+2304 \alpha^{3} \delta-2568 \alpha^{2} \delta^{2}$ $+784 \alpha \delta^{3}+1152 \alpha^{3} \delta^{2}-1280 \alpha^{2} \delta^{3}+356 \alpha \delta^{4}-36 \delta^{4}$.

Noting that $\alpha>\delta$, using MATLAB 7.0, we have that $\partial p_{u} / \partial \delta$ is positive. Hence, the price of first-generation used product increases in the durability $\delta$.

Following the similar analysis, we have $\partial p_{2} / \partial \delta<$ 0 . Therefore, the price of second-generation new product decreases in the durability $\delta$.

Proof of Proposition 8. For the sign of $\partial p_{1} / \partial \alpha$, we have

$$
\begin{aligned}
\frac{\partial p_{1}}{\partial \alpha}=2 \delta(1+\delta)( & 256 c \alpha^{2}+256 c \alpha \delta-256 c \alpha \delta^{2} \\
+ & 22 \delta^{3}+18 \delta^{4}+160 \alpha^{2} \delta \\
+ & \left.156 \alpha^{2} \delta^{2}-64 c \delta^{2}-63 c \delta^{3}\right)
\end{aligned}
$$

$$
\begin{aligned}
& \times\left[128 \alpha^{2}(1+\delta)-144 \alpha \delta\right. \\
& \left.\quad+40 \delta^{2}-145 \alpha \delta^{2}+41 \delta^{3}\right]^{-2} .
\end{aligned}
$$

It is worth noting that $\alpha>\delta$, and we have that $\partial p_{1} / \partial \alpha$ is positive. Hence, the price of first-generation new product increases in the degree of quality improvement $\alpha$.

For the sign of $\partial p_{2} / \partial \alpha$, we have

$$
\begin{aligned}
\frac{\partial p_{2}}{\partial \alpha}= & 2 \delta(1+\delta) \\
& \times\left(256 c \alpha^{2}+256 c \alpha \delta-256 c \alpha \delta^{2}+22 \delta^{3}\right. \\
& \left.+18 \delta^{4}+160 \alpha^{2} \delta+156 \alpha^{2} \delta^{2}-64 c \delta^{2}-63 c \delta^{3}\right) \\
& \times\left[128 \alpha^{2}(1+\delta)-144 \alpha \delta\right. \\
& \left.+40 \delta^{2}-145 \alpha \delta^{2}+41 \delta^{3}\right]^{-2} .
\end{aligned}
$$

It is worth noting that $\alpha>\delta$, and we have that $\partial p_{2} / \partial \alpha$ is positive. Therefore, the price of second-generation new product increases in the degree of quality improvement $\alpha$.

For the sign of $\partial p_{u} / \partial \alpha$, we have

$$
\begin{gathered}
\frac{\partial p_{u}}{\partial \alpha}=2 \delta\left(832 \alpha^{2} \delta+244 \delta^{3}-896 \alpha \delta^{2}\right. \\
+22 \delta^{3}+536 \delta^{4}+291 \delta^{5}+1760 \alpha^{2} \delta^{2} \\
\left.+927 \alpha^{2} \delta^{3}-1936 \alpha \delta^{3}-1038 \alpha \delta^{4}+c f\right) \\
\times\left[128 \alpha^{2}(1+\delta)-144 \alpha \delta\right. \\
\left.+40 \delta^{2}-145 \alpha \delta^{2}+41 \delta^{3}\right]^{-2}
\end{gathered}
$$

where $f=512 \alpha \delta-1088 \alpha^{2} \delta+1152 \alpha \delta^{2}-576 \alpha^{2} \delta^{2}+640 \alpha \delta^{3}-$ $128 \delta^{2}-306 \delta^{3}-178 \delta^{4}$.

Noting that $\alpha>\delta$, using MATLAB 7.0, we have that $\partial p_{u} / \partial \delta$ is positive. Hence, the price of first-generation used product increases in the degree of quality improvement $\alpha$.

Proof of Proposition 9. Substituting $p_{1}^{*}, p_{2}^{*}$, and $p_{u}^{*}$ into the manufacturer's two-period optimization problem $\operatorname{Max} \Pi\left(p_{1}\right)=\Pi_{1}\left(p_{1}\right)+\Pi_{2}^{*}\left(p_{1}\right)$, we have

$$
\begin{gathered}
\Pi_{m}=2\left(23 \alpha \delta^{2}+26 \alpha^{2} \delta^{2}+32 \alpha^{4} \delta+60 \alpha^{2} \delta^{3}+6 \alpha \delta^{3}+32 \alpha^{4}\right. \\
\left.+16 \alpha^{3}+\delta^{5}-4 \delta^{4}-34 \alpha^{2} \delta-60 \alpha^{3} \delta+c f\right) \\
\times((\alpha-\delta) \\
\times\left(128 \alpha^{2}(1+\delta)-144 \alpha \delta\right. \\
\left.\left.+40 \delta^{2}-145 \alpha \delta^{2}+41 \delta^{3}\right)\right)^{-1}
\end{gathered}
$$


where $f=8 \alpha^{2} \delta-8 c \alpha \delta+37 \alpha \delta^{2}-62 \alpha^{2} \delta+32 \alpha^{3} \delta-62 \alpha^{2} \delta^{2}+$ $37 \alpha \delta^{3}+32 \alpha^{3}-5 \delta^{3}+2 \delta^{2}+8 \alpha^{2}-8 \alpha \delta^{2}$. Because $\alpha>\delta$, using MATLAB 7.0, we have that $\partial \Pi_{m} / \partial \alpha>0$ is positive. Hence, the profitability of the manufacturer increases in the degree of quality improvement $\alpha$. That is, the existence of the secondary market actually increases the manufacturer's profitability and drives the manufacturer to launch an innovative new product in the second period.

\section{Conflict of Interests}

The authors declare that there is no conflict of interests regarding the publication of this paper.

\section{Acknowledgments}

This research has been supported by the National Natural Science Foundation of China (71271225 and 71301178), Chongqing's Natural Science Foundation (cstc2012jjA00036), and the Open Fund of Chongqing Key Laboratory of Logistics (CQKLL12001).

\section{References}

[1] Consumer Business Review, "Big Players Emerge in Fragmented Brokerage Market. CBRonline.com," 2005, http:// www.cbronline.com/news/big_players_emerge_in_fragmented brokerage_market.

[2] J. Marion, "Sun under fire-For fixing Solaris OS costs to reduce competition in used Sun market," Association of Service and Computer Dealers International (ASCDI), 2004, http:// www.sparcproductdirectory.com/view56.html.

[3] E. Dourado, 2010, http://elidourado.com/blog/free-engraving/.

[4] J. Riley and W. F. Samuelson, "Optimal auctions," The American Economic Review, vol. 71, no. 3, pp. 381-392, 1981.

[5] P. Milgrom and R. J. Weber, "A theory of auctions and competitive bidding," Econometrica, vol. 50, no. 5, pp. 1089-1122, 1982.

[6] S. P. Anderson and V. A. Ginsburgh, "Price discrimination via second-hand markets," European Economic Review, vol. 38, no. 1, pp. 23-44, 1994.

[7] A. Dhebar, "Durable-goods monopolists, rational consumers and improving products," Marketing Science, vol. 13, no. 1, pp. 100-120, 1994.

[8] P. Desai and D. Purohit, "Leasing and selling: optimal marketing strategies for a durable goods firm," Management Science, vol. 44, no. 11, pp. S19-S34, 1998.

[9] P. S. Desai and D. Purohit, "Competition in durable goods markets: the strategic consequences of leasing and selling," Marketing Science, vol. 18, no. 1, pp. 42-58, 1999.

[10] S. Huang, Y. Yang, and K. Anderson, "A theory of finitely durable goods monopoly with used-goods market and transaction cost," Management Science, vol. 47, no. 11, pp. 1515-1532, 2001.

[11] Y. Xiong, W. Yan, K. Fernandes, Z.-K. Xiong, and N. Guo, "Bricks versus clicks: the impact of manufacturer encroachment with a dealer leasing and selling of durable goods," European Journal of Operational Research, vol. 217, no. 1, pp. 75-83, 2012.

[12] D. A. Levinthal and D. Purohit, "Durable goods and product obsolescence," Marketing Science, vol. 8, no. 1, pp. 35-56, 1989.

[13] D. Fudenberg and J. Tirole, "Upgrades, tradeins, and buybacks," RAND Journal of Economics, vol. 29, no. 2, pp. 235-258, 1998.
[14] W. S. Lim and C. S. Tang, "Optimal product rollover strategies," European Journal of Operational Research, vol. 174, no. 2, pp. 905-922, 2006.

[15] A. Dhebar, "Durable goods monopolists, rational consumers, and improving products," Marketing Science, vol. 13, no. 1, pp. 100-120, 1994.

[16] L. J. Kornish, "Pricing fora durable-goods monopolist under rapid sequential innovation," Management Science, vol. 47, no. 11, pp. 1552-1561, 2001.

[17] J. J. Anton and G. Biglaiser, "Quality, upgrades and equilibrium in a dynamic monopoly market," Working Paper, Duke University, 2011.

[18] P. S. Desai, O. Koenigsberg, and D. Purohit, "Strategic decentralization and channel coordination," Quantitative Marketing and Economic, vol. 2, no. 1, pp. 5-22, 2004.

[19] S. R. Bhaskaran and S. M. Gilbert, "Selling and leasing strategies for durable goods with complementary products," Management Science, vol. 51, no. 8, pp. 1278-1290, 2005.

[20] C. Friscia, Retail Business Operations, New Providence, New Jersey, NJ, USA, 2009.

[21] S. Yin, S. Ray, H. Gurnani, and A. Animesh, "Durable products with multiple used goods markets: product upgrade and retail pricing implications," Marketing Science, vol. 29, no. 3, pp. 540560, 2010.

[22] N. Oraiopoulos, M. E. Ferguson, and L. B. Toktay, "Relicensing as a secondary market strategy," Management Science, vol. 58, no. 2, pp. 1022-1037, 2012. 


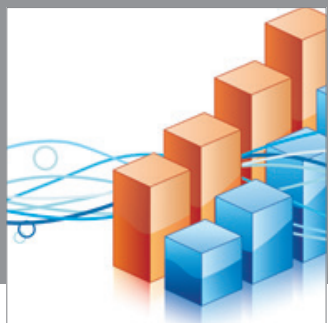

Advances in

Operations Research

mansans

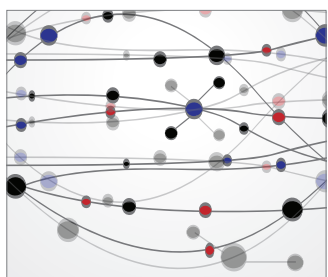

The Scientific World Journal
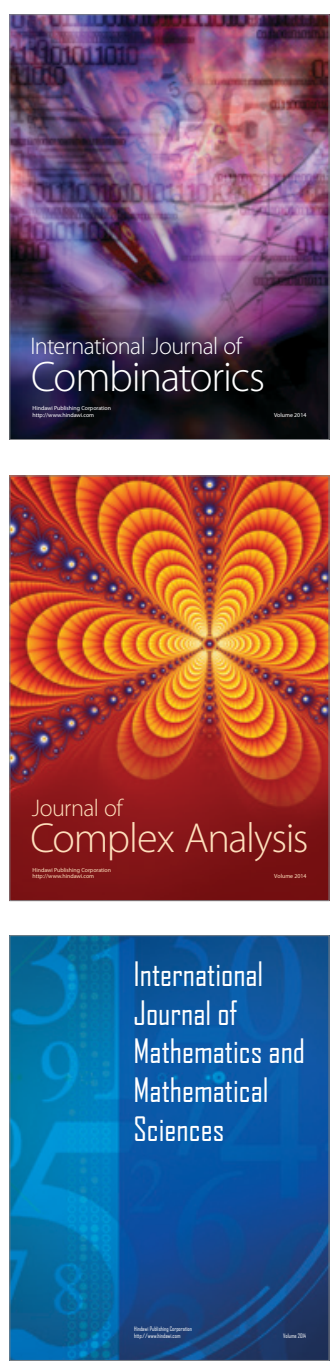
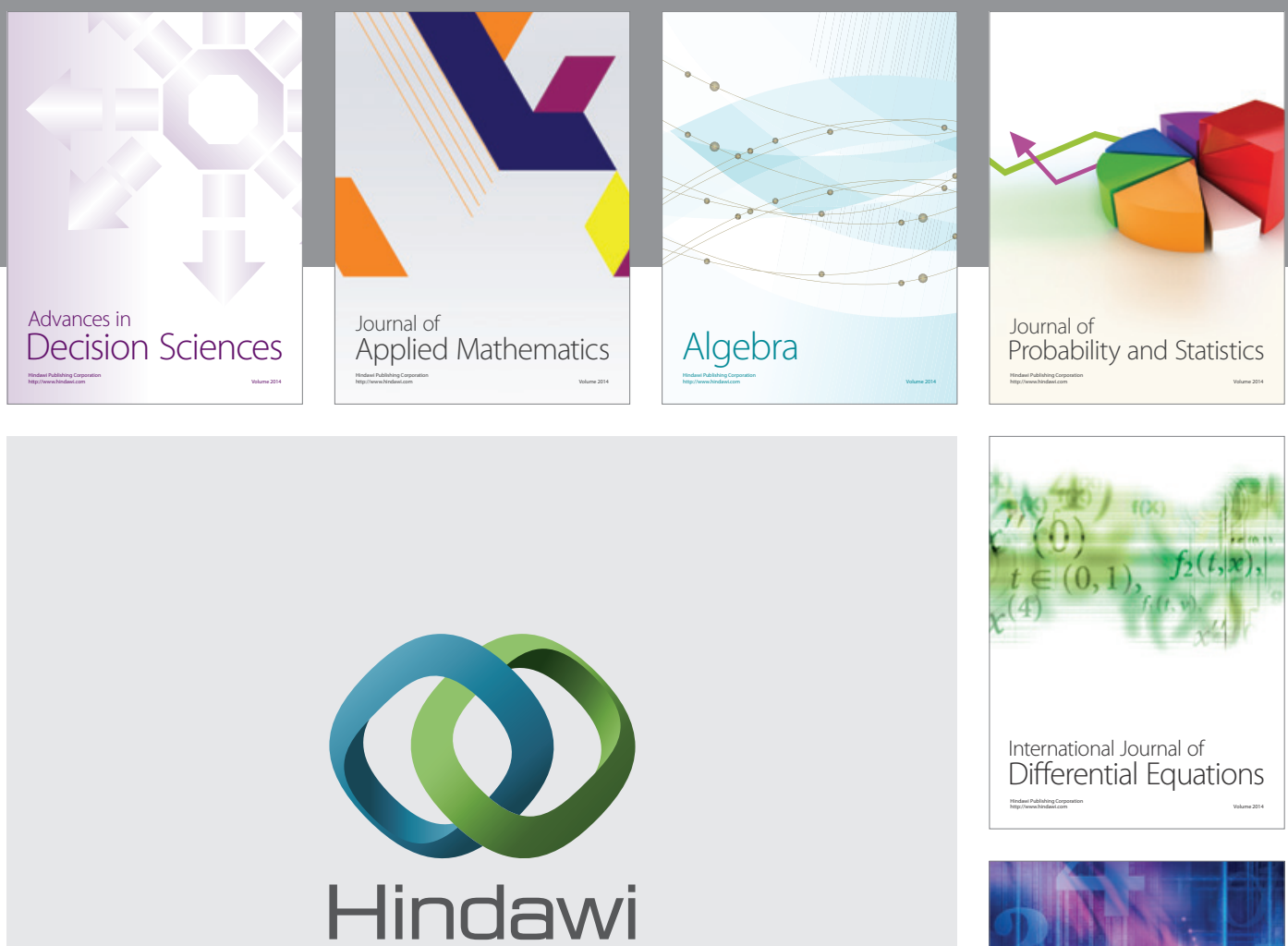

Submit your manuscripts at http://www.hindawi.com
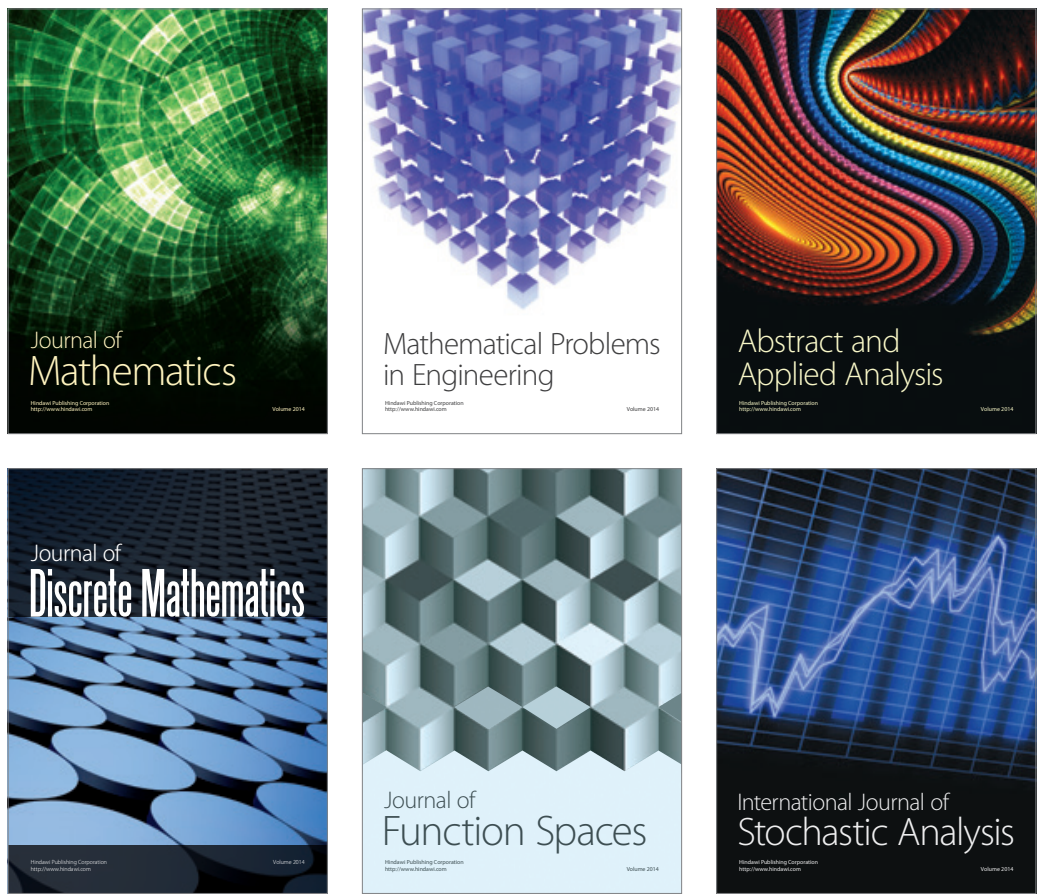

Journal of

Function Spaces

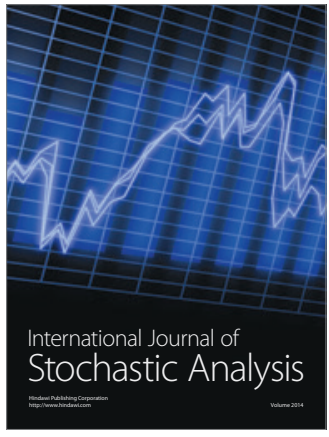

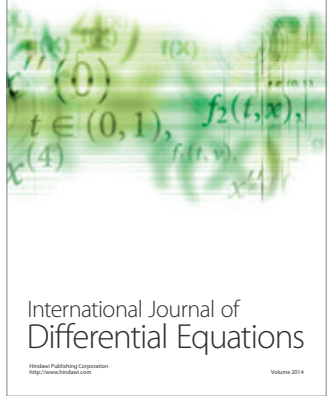
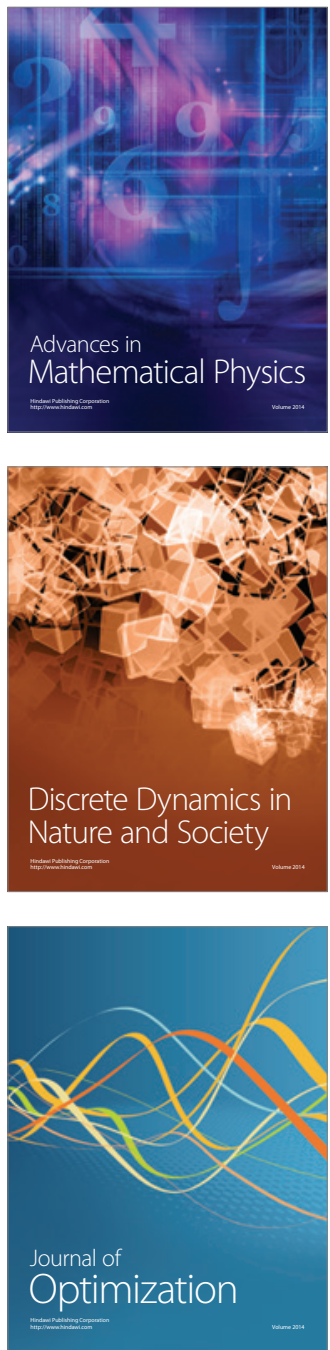